\title{
Representações Sociais no Território de Elísio Medrado Marcada pelas Práticas de Prostituição das Mulheres 'Rapa-Bolso'
}

\author{
Social Representations of the Territory Elísio Medrado, Marked by the \\ Prostitution Practices of the 'Rapa-Bolso' Women
}

\author{
Renilton da Silva Sandes \\ Univesidade do Estado da Bahia \\ rsandes.uneb@yahoo.com.br
}

\begin{abstract}
Resumo
Este estudo tem como objetivo compreender as representações sociais de Elísio Medrado - cidade do Recôncavo baiano - sobre as mulheres 'rapabolso', majoritariamente negras, que tiveram um protagonismo na construção de territórios, através das práticas de prostituição na Bahia escravocrata, nas décadas de 1930 a 1940. A proposta da pesquisa é a construção de uma Geografia do Gênero, bastante inovadora no âmbito acadêmico, que analise as diferenciações da utilização dos espaços e territórios alternativos de prostituição e as relações de poder 'contra-hegemônico' que, neles, as mulheres estabeleceram, determinando com suas práticas cotidianas às organizações territoriais das ruas, assim como dando nomes a elas e até a própria cidade, então povoada, que passou a ser chamado de Rapa Bolso, precisamente, por serem elas as que 'rapavam o bolso' de seus clientes.
\end{abstract}

Palavras-chave: Geografia do gênero; representação social; território.

\begin{abstract}
This study aims to understand the social representations of Elysium Medrado - a city in the Bahian Reconcavo, Brazil - on the 'rapa-bolso' women, mostly black famales, who had a role in the construction of territories through the practices of prostitution in the slavocrat Bahia, in the decades of 1930 to 1940 . The proposal of this research is to build a Geography of Gender, which is very innovative in the academic environment, in order to analyze the differences in the use of alternative spaces and prostitution areas, and the 'counter-hegemonic' power relations there established by the women, demarcating, with their daily practices, the territorial organization of the streets and naming them, as well as naming the city itself, then a town, which became known as Rapa Bolso (Drain Pocket) precisely because they are the ones that 'drained the pocket' of their customers.
\end{abstract}

Keywords: Geography of gender, social representation; territory. 
Representações Sociais no Território de Elísio

Medrado Marcada pelas Práticas de Prostituição

das Mulheres 'Rapa-Bolso'

\section{Introdução}

Este estudo tem como objetivo compreender as representações sociais da comunidade de Elísio Medrado - cidade do Recôncavo baiano situado entre Santo Antônio de Jesus e Amargosa, com uma população de 8 mil habitantes. Sobre as mulheres, majoritariamente negras, que tiveram um protagonismo na organização do território do município, antigo povoado do 'Rapa-Bolso' através das práticas de prostituição na Bahia escravocrata de finais do século XIX até a metade do século XX. Nessa perspectiva, a pesquisa também objetiva analisar até que ponto essa realidade histórica continua determinando a geografia do gênero no município, buscando um outro olhar ou outros olhares, através da memória, da história oral e das falas nas entrevistas abertas e nos grupos de discussão que darão voz aos atores sociais, mulheres e homens, que vivenciaram o cotidiano das mulheres 'rapa bolso'.

A proposta da pesquisa é a construção de uma Geografia do Gênero, bastante inovadora no âmbito acadêmico, que analise as diferenciações da utilização dos espaços e territórios alternativos de prostituição e as relações de poder 'contra-hegemônico' que, neles, as mulheres estabeleceram, determinando com suas práticas cotidianas as organizações territoriais das ruas assim como dando nomes a elas e até à própria cidade, então povoado, que passou a ser chamado de Rapa Bolso, precisamente, por ser elas as que 'rapavam o bolso' de seus clientes. Algumas de estas mulheres ainda são vivas, e todas elas estão muito presentes no imaginário coletivo de Elísio Medrado.

O objetivo deste trabalho é refletir sobre a condição da mulher prostituta a partir das considerações feitas pela geografia do gênero, que aborda a dimensão espacial das relações de gênero. Segundo Claval (1999), estudos da geografia do gênero se apegam ao fato de que há diferenças culturais entre o masculino e o feminino na maneira de conceber o mundo e vivê-lo. Dessa forma, não podemos separar a categoria gênero das relações políticas, econômicas, sociais, culturais e raciais, pois é inconcebível um universo consensual entre as mulheres que desconsidera suas particularidades.

Acreditamos, desde já, que este trabalho coloca a ciência geográfica em movimentos, revelando espaços e territórios antes não pensados. Nossa intenção é, sobretudo, a partir da sistematização da ideia de território, problematizar e ampliar a esfera do debate sobre a geografia do gênero, visando enriquecer $o$ nosso diálogo com outras ciências sociais. Essa questão, de fato, oferece diferentes desafios para a geografia e para o geógrafo que tem o território como categoria de análise e necessita estudá-lo para contribuir com sua compreensão e transformação.

\section{O Território como Cenário das Representações Sociais}

No âmbito da ciência geográfica, muitos geógrafos têm trabalhado com o conceito de território a partir de uma leitura restrita e pobre da realidade, sem abranger as esferas e contextos políticos e sócio-históricos. Recentemente, diversas áreas do conhecimento adotaram o território como categoria essencial em suas análises. Todavia, o conceito de território é utilizado como uma dimensão das relações sociais permeada por uma teia de significados políticos marcado pelo poder. Portanto, como afirma Campos (2005, p.63), sabemos que "historicamente os grupos dominantes, produziram o inusitado: a 'estigmatização dos espaços e territórios' apropriados pelas classes subalternas". Em nosso caso concreto, as prostitutas são consideradas 'classes perigosas' ao longo da história, justamente por representar o diferente, o outro, no que se refere à ocupação e o uso das mais distintas áreas geográficas.

É obvio que a representação social que os atores fazem não esgota o conteúdo do território. Assim, a representação compõe o cenário, tendo o território como o espetáculo da tomada original do poder. Raffestin (1993, p.144) nos fala que a construção do território é marcada pelas relações de poder exercido por pessoas ou grupos sociais, mediada pelas ações políticas do trabalho humano no espaço. Nesse sentido, o autor entende o território como sendo:

Um espaço onde se projetou um trabalho seja energia e informação, e que por consequência, revela relações marcadas pelo poder. O território se apoia no espaço, mas não é o espaço. É uma produção a partir do espaço.

Isso nos faz entender que o território é a materialização da existência humana, envolvida por uma ordem de subjetividade individual e coletiva. Vale ressaltar que, o território nesse sentido, passa a ser compreendido segundo as relações sociais, econômicas e culturais que o criou e o mantém a partir de uma forma de poder.

O espaço é a matéria-prima que o ator utiliza para produzir o território. Assim, a transformação do espaço em território acontece por meio da conflitualidade, definida pelo estado permanente de negociações geradas no enfrentamento entre as forças políticas que procuram criar, conquistar e controlar certas porções

Renilton da Silva Sandes 
do território. É no bojo desse contexto que emergem as análises sobre as ações políticas cotidianas das prostitutas. Portanto, essas atrizes sociais fazem a ocupação e o uso do território não apenas como um trunfo de marcar uma área, mas também como meio essencial de elaboração de suas estratégias de sobrevivências, frente à exclusão social que são postas pelas classes dominantes.

O território também pode ser construído a partir das representações que os atores sociais fazem a seu respeito. As leituras sobre representação social de Goffman (1985) nos ajudam a interpretar as falas, práticas e ações construídas acerca das impressões da realidade que nos é dada, entendida como atividade que exerce uma influência constante sobre um grupo particular de observadores. Já as reflexões sobre representações sociais pautadas no pensamento de Roger Chartier (1990) nos permitem compreender como esta realidade social é construída e pensada em diferentes lugares.

Desde essa compreensão Haesbaert (2002) analisa o território numa perspectiva culturalista, priorizando dimensões simbólicas e mais subjetivas. O território para ele é visto fundamentalmente como produto da apropriação feita através do imaginário, das representações e da identidade territorial e social sobre o espaço, ou seja, da identificação que determinados grupos sociais desenvolvem com seus espaços vividos. $\mathrm{O}$ autor também nos alerta que esse espaço que compõe nossas relações cotidianas, com seus muros, fronteiras, limites, imagens, é o grande universo em que, ali e aqui, procuramos desenhar nossos 'territórios alternativos' de inclusão social. Ao respeito é relevante retomar, também aqui, a Santos (1999) quando explica que enquanto para os atores hegemônicos o território usado é visto como um recurso, na garantia da realização de seus interesses particulares, para os atores contra-hegenônicos, trata-se de um abrigo, buscando constantemente se adaptar ao meio geográfico local, ao mesmo tem em que estes recriam estratégias que garantam sua sobrevivência nos lugares.

Em relação ao nosso caso concreto, sobre as práticas de prostituição das mulheres rapa-bolso, elas marcam seu território em virtude das necessidades que lhes permitam minimamente a sobrevivência nas ruas do povoado Rapa Bolso e enquanto espaço delimitado e controlado, através do qual se exerce um determinado poder, mediatizado pelas relações sociais, econômicas e simbólico-culturais, como integração entre um sistema de objetos e um sistema de ações.

Compreender as dimensões do conceito de território é importante para a superação de preconceitos contra os sujeitos sociais que lutam por suas existências na conquista de seus espaços e territórios alternativos. Muitas vezes estes sujeitos, atores e atrizes, são denominados de baderneiros, perturbadores da moral, dos bons costumes e da ordem social vigente, porque mexeram, entraram, penetraram em espaços e territórios de onde foram excluídos e que, por causa da desigualdade econômica e do controle social, não poderiam entrar e permanecer em seus territórios.

Nesse contexto, também é possível mapear as ações do poder hegemônico sobre o espaço geográfico, transformando as paisagens, criando e destruindo espaços, territórios estigmatizando-os. A leitura geográfica é estratégica e fundamental para o desenvolvimento das intencionalidades que nascem e fazem nascer relações sócias espaciais e sócias territoriais. Igualmente, nos ajuda a compreender como a Geografia do Gênero pode utilizar uma leitura autônoma, para compreender melhor à realidade da territorialidade das práticas da prostituição, no povoado Rapa Bolso. Portanto, os conceitos de gênero e geografia do gênero são tentativos de desfragmentação das análises relacionadas aos espaços e territórios. Pode-se fazer uma leitura mais ampla a partir desses conceitos, mas esta sempre será uma leitura parcial, porque a totalidade da realidade é um processo individual e coletivo que só pode ser compreendido no movimento de todos.

\section{Geografia do Gênero e Prostituição}

$\mathrm{Na}$ esfera da vida cotidiana mulheres e homens pensam, agem, sentem e fazem usos e experiências diferenciais dos territórios e espaços de modo completamente distintos. Esse é o desafio colocado para o pesquisador da Geografia do Gênero - um ramo cujo objetivo, assim nos falam Martinez et al (1995, p.17-18), "não é fazer uma geografia das mulheres igual não teria sentido fazer uma geografia dos homens ou da população de cor - mas, incitar a uma interpretação da geografia desde um perspectiva de gênero". Poderemos então falar com propriedade sobre a força das mulheres na produção, reprodução e transformação dos espaços territórios que, por sua vez, são espaços portadores de um sentido e uma função representados pelas ações sociais das mulheres e mediatizado pelas relações de poder derivadas das diferenças de gênero.

É trilhando esse caminho que esta pesquisa se insere, pois buscará analisar a manutenção da condição de subalternidade feminina nos distintos territórios usados e praticados nos espaços urbanos, como se fossem um caminho natural e não uma construção simbólica, cultural, arraigada na história da 
humanidade. Um simbolismo que tem no alicerce a conservação das desigualdades entre homens e mulheres e ocasiona diferentes oportunidades entre ambos.

As relações de gênero que permeavam o cenário da sociedade colonial tinham como pano de fundo a sustentação da ordem na manutenção do poder do homem sobre a mulher de um modo geral. Nesse contexto, o papel representado pelas mulheres, especificamente as negras que eram estigmatizadas pelo caráter corrosivo da moralidade e dos bons costumes pregados pelo poder patrimonialista estabelecido, ficavam a mercê de autonomia e submissas às relações de mando e obediência de seus maridos e respectivamente seus senhores. Sobre essas práticas rotineiras, assim Saffioti (1976, p.164), argumenta: "cabia a escrava, além de uma função no sistema produtivo de bens e serviços, cumprir a função de mero instrumento de prazer sexual de seu senhor". A leitura que se faz implica em compreender que o papel da mulher negra nessa ordem completava toda a exploração econômica que seu senhor tinha direito de fazer. Contudo, utilizada como trabalhadora, como reprodutora da força de trabalho, a mulher negra estava sujeita ainda aos expedientes do aluguel de seu corpo para o comércio erótico, o que fechava o círculo de exploração de seu senhor sobre sua 'mercadoria'.

As razões da disseminação das práticas de prostituição no período colonial eram justificadas por vários fatores. Dificuldades de toda ordem rondaram o cotidiano das classes sociais menos favorecidas e, em consequência, muitas mulheres entregavam-se a prostituição devido à ausência do trabalho feminino e de uma sólida base familiar. Segundo Saffioti (1976, p. 170-172):

$\mathrm{Na}$ época escravocrata, entretanto, o grosso da prostituição, formaram-no as negras, alugadas que eram pelos seus senhores, numa exploração completa da escravidão. É bem verdade que muitas mulheres, oprimidas pelo pai ou marido, contribuíram para a formação de uma contracorrente de irregularidades sexuais para os desejos e sentimentos não passíveis de manifestação dentro dos limites da família patriarcal.

Basta lembrar que, remontando ao fim da abolição da escravidão significou inúmeras consequências para a vida das mulheres tanto da camada senhorial como da classe inferior. Vale salientar que, tanto no período colonial como na República, é obvio que a preservação do modelo de família nuclear patriarcal sustentado nos valores tradicionais - virgindade, castidade, casamento
- da imensa maioria das mulheres da camada alta da sociedade foi possível graças à prostituição de outras mulheres. No novo regime político, a prostituição da mulher negra continuaria, mas, não em virtude de sua condição de escrava e sim por motivos, em grande parte, econômicos, um dos elementos mais significativos do comércio do sexo.

Nesse ínterim, Beauvoir (1987) argumenta ser ingênuo perguntar que motivos levam à mulher a prostituição. No entanto, para a autora, o fenômeno da prostituição é bastante complexo, uma das profissões mais antigas do mundo compreendidas por distintos fatores, a partir dos fantasmas que o cercam, e que não pode ser confundida com criminalidade. A autora descreve uma gama variada de razões que levam as mulheres ingressarem no universo da prostituição, tais como:

Serventes de casas de prostituição, explorada, escravizada e tratada antes como objeto que como pessoa, a servente era para 'todo serviço', marginalizadas socialmente, defloradas, por horror a sua sexualidade nascente, por alguma enfermidade onde a mulher fica incapaz de realizar um outro trabalho, quando nasce um filho onde a mãe solteira converte-se numa prostituta para nutrir seu filho, rancor familiares muitas jovens que são prostitutas, abandonadas por seus pais, começam sendo mendigas e ali passam a fazer a vida na rua (BEAUVOIR, 1987, p. 341).

O olhar vigilante da igreja se fez sentir sobre essas práticas. $\mathrm{O}$ discurso religioso era caracterizado por uma intensa repressão à sexualidade em todas as suas formas, pois era necessário domesticar a mulher dentro do casamento, para moldar à forma perversa de seu comportamento. Assim ao que consta, Priore (1988, p.16) nos alerta que: "a ideia de adestrar a sexualidade dentro do 'tálamo conjugal' decorre do interesse de fazer da família o eixo irradiador da moral cristã". A preocupação com a pureza física e mental do poder hegemônico estabelecido,atua sobre o corpo da prostituta na colônia de forma a discipliná-la, fazendo assim a manutenção da normatização desses corpos. Para Priore (1988,) o que se observa é a formação de uma hipocrisia social a luz das posições desse sistema normativo, pois na prática, a moral sexual que se estabeleceu na colônia era de um tipo diferente dos preceitos teoricamente ditados pela igreja.

Em resposta ao discurso religioso moralizador dos corpos, a igreja católica assistiu na colônia à formação dos concubinatos, mancebias e prostituição

Renilton da Silva Sandes 
comportamentos contrários a moral sexual brasileira. Em contraposição a essa realidade, a velada cumplicidade com a prostituição tanto do poder religioso como do poder patriarcal, era defendida segundo o argumento de que uma boa ordem familiar dependia de um meretrício organizado. Dessa forma, esclarece Priore (1988, p. 22):

Este [o meretrício] deveria pacificar os ânimos [dos homens] nos bordéis com mulheres públicas e postas a ganho, cuja sexualidade era uma mercadoria que caracterizasse o seu ofício. A prostituição, embora aparentemente transgressora constituía-se numa prática a serviço da ordem sócio espiritual.

A territorialidade do meretrício era tão comum na colônia que passava longe dos esforços metropolitanos de conter o nascimento de mestiços, fato que tanto afligia as autoridades coloniais. Assim, relata Priore (1988, p.22): "mais do que perseguidas por seu ofício, as meretrizes são perigosas por engendrarem uma prole ilegítima, pois concebida fora do casamento e miscigenada, porque contrariava o ideal da 'pureza de sangue' tão caro aos colonizadores".

\section{Representações Sociais so bre o Povoado do Rapa-Bolso, atual Município de Elísio Medrado}

O lugar, aqui localizado, é a sede do município de Elísio Medrado - ainda Recôncavo baiano, que fica situado entre Santo Antônio de Jesus e Amargosa, tendo uma população estimada em 2008 de aproximadamente 8 mil habitantes com uma densidade demográfica $78,22 \mathrm{hab} / \mathrm{Km}^{2}$, totalizando $73 \%$ da população predominantemente na zona rural e $27 \%$ na zona urbana, segundo projeções do IBGE (2008). O município de Elísio Medrado está localizado na Microrregião Homogênea de Feira de Santana, na Bacia Hidrográfica do Recôncavo Sul. A sede do município de Elísio Medrado fica a uma distância de $224 \mathrm{Km}$ de Salvador, por via rodoviária BR 101 e BR 324 em estrada pavimentada e em linha reta $108 \mathrm{Km}$, e no acesso via Ferry Boat com $135 \mathrm{Km}$. Tendo como ponto de convergência com a rodovia estadual, a BA 246 liga esta cidade ao terminal hidroviário de Bom Despacho aos municípios de Santo Antônio de Jesus e Amargosa.

Segundo o Arquivo Público Municipal, a história do município de Elísio Medrado remonta à época da colonização brasileira por volta do século XVI, quando bandeirantes penetraram na região em busca de riquezas minerais, sobretudo a prata, pedras preciosas e semipreciosas, indígenas para escravização ou extermínio de quilombos. Por vezes, o reconhecimento do território para a Coroa Portuguesa e o controle de levantamentos dos índios era também objetivo dos bandeirantes. O principal deles, Gabriel Soares organizou uma bandeira exploradora em 1591 que construiu uma fortaleza, na Vila de Pedra Branca, para armazenar mantimentos, armas e munições, para combater e aldear os 'ferozes' índios Cariris e Sabujas que povoavam a região e constituíam uma 'ameaça' ao processo de colonização.

No entanto, o povoamento efetivo só ocorreu em 1900, com a chegada de agricultores que ali se estabeleceram em virtude da fertilidade das terras e passaram a cultivar uma produção agrícola voltada para a cana de açúcar, feijão, fumo e café. O município foi criado com os territórios dos distritos de Monte Cajueiro com a denominação de São Francisco do Cajueiro em 1900, mudada para Sousa Peixoto em 1938 e, posteriormente pelo Decreto Estadual de 30/10/1953 mudou o nome para Novo Paraíso, e Elísio Medrado em 1962, desmembrado do município de Santa Terezinha. O Deputado José Medrado apresentou ao Legislativo Estadual um projeto de Lei $\mathrm{n}^{\circ}$ 224/62, após sua aprovação esse projeto transformou-se na Lei $\mathrm{n}^{\mathrm{o}} 1741$ de 20/07/1962 sancionado pelo então Governador Juracy Magalhães e publicada no Diário Oficial de 24/07/1962. O município foi criado pela Lei Estadual de 20/07/1962, passando a se chamar de Elísio Medrado, desmembrando-se de Santa Terezinha. Esse nome foi dado em homenagem ao médico Elísio Medrado, muito influente em Santa Terezinha (ARQUIVO PÚBLICO).

Referente à origem do nome 'Rapa Bolso', não se sabe ao certo o período em que este surgiu. A construção simbólica do referido nome e material desse espaço e território alternativo de prostituição é carregado de significados, permeado por curiosidades, inquietações e interrogações. Ora, este nome é caracterizado por um saudosismo facial expresso pelas risadas dos homens, como um tempo e um espaço de puro prazer; ora, desprezado pelos olhares sombrios e caras fechadas das mulheres de família, que retorciam seus corpos no sofá, enquanto suas mãos tremiam de raiva, sendo possível perceber que na profundidade de sua respiração era refletido o incomodo de cada pergunta que era lançada sobre o dia a dia das mulheres 'rapa bolso', numa clara insatisfação por estar evocando uma memória que elas fazem questão de apagar do seu subconsciente.

Renilton da Silva Sandes 


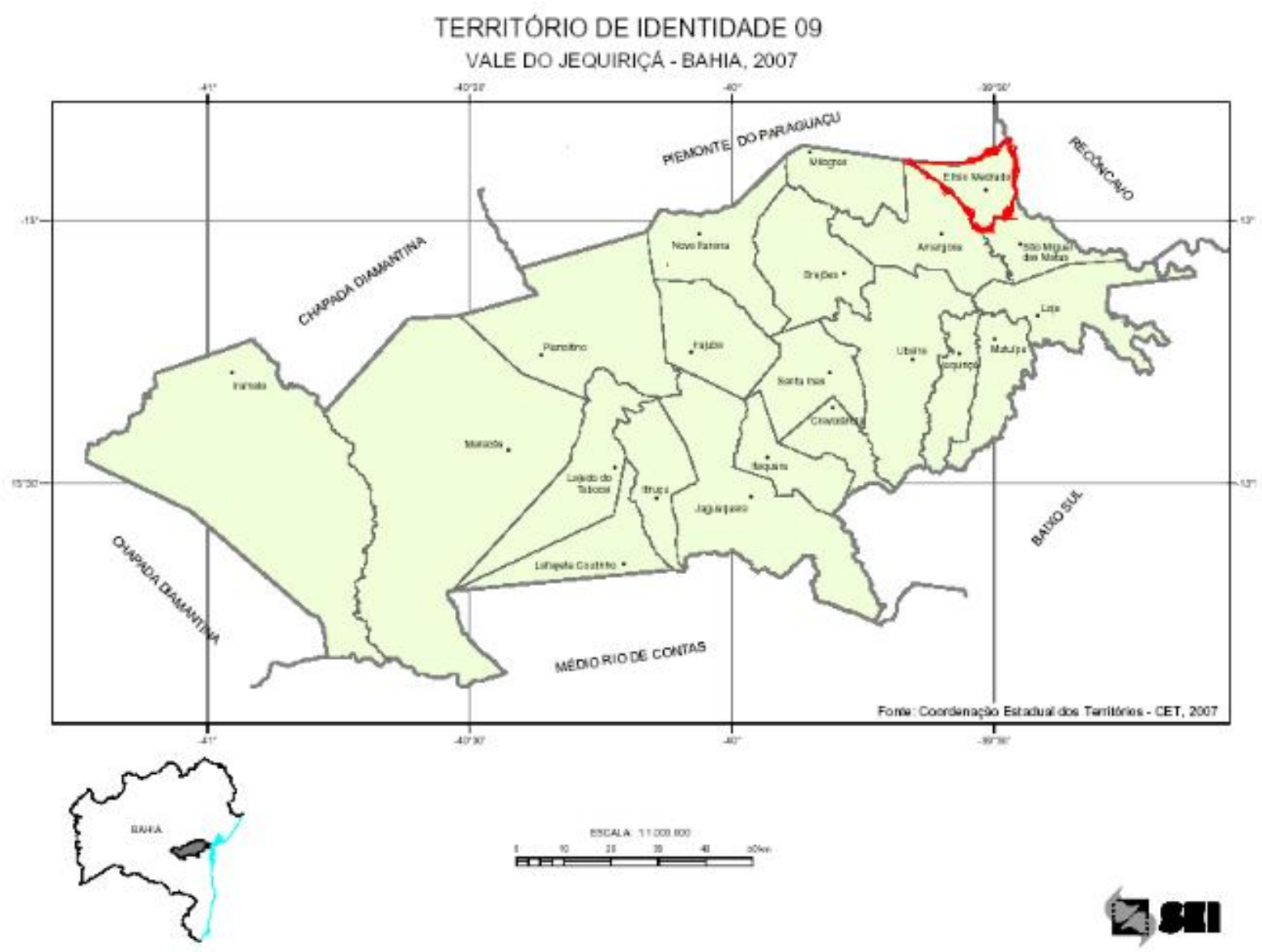

A data de seu nascimento parece que foi esquecido no tempo e no espaço, 'sepultado e apagado' da memória da história do município, embora este nome seja fruto de três versões bem distintas. De acordo com os documentos presentes no Arquivo Público Municipal, a primeira, versão, é sustentada pela existência de um pequeno comércio de roupa e alimentação (secos e molhados), no qual os produtos eram bastante caros e por essa razão acabavam 'rapando o bolso' dos fregueses locais e de outros lugares. Segundo uma antiga moradora do Rapa Bolso, o nome foi dado por conta da migração de donos de bancas de jogos de azar, como: roletas, dados, baralhos, jaburu que vinham de outras cidades nos finais de semana e em dias de festas para o povoado, e que esses jogos, 'rapavam o bolso' dos homens que vinham para rua fazer suas feiras tomando assim seu dinheiro. Quando buscavam alcançar os prêmios oferecidos por esses jogos, que eram galinhas, perus, doces e brinquedos.

Uma outra versão, recolhida em vários depoimentos, diz respeito à existência de um número considerável de 'mulheres da vida', as quais 'rapavam os bolsos' dos mais distintos clientes, tais como: fazendeiros, comerciantes, delegado, inspetor, políticos, tropeiros, quando iam para a feira nos dias de sábado, como afirmam os seguintes depoimentos: "O Rapa Bolso é de muitos anos, não se sabe quando começou. Aqui tinha muita pobreza. Tinha muita rapariga, meretriz, muita mulher ruim, que rapava o dinheiro dos homens". "Pelo que minha mãe contava é que se dava o nome de Rapa Bolso porque as mulheres da vida devoravam e sugavam o dinheiro dos homens". 2

A leitura que se faz da dinâmica do nome Rapa Bolso é permeada por relações econômicas, sociais, políticas e culturais. Os documentos e depoimentos 
revelam que o significado do nome Rapa Bolso varia, pois as ideias de comércio, das apostas em jogos de azar e da prostituição estavam ao serviço dos interesses das mais distintas classes sociais, construindo assim as fantasias individuais e coletivas elaboradas pelas imagens que pintavam o espaço cotidiano desses sujeitos sociais.

Esses fatores mais tarde fizeram ecoar as vozes a favor das medidas de higienização física e moral e de civilização nos espaços públicos, como valores a serem impostos, abertamente apoiada pelo pensamento político, religioso e pelo modelo de família nuclear. Assim, o povoado foi evoluindo e o seu nome mudado de Rapa Bolso, pelo Decreto Estadual de 30/10/1953 passando agora a ser chamado de Novo Paraíso.

Pelo que consta, os depoimentos orais nos asseveram que, a prática do agenciamento de mulheres para a prostituição no povoado Rapa Bolso estava assentada no personagem de José Veneno que, fazia e alugava as casas de palhas e traziam as prostitutas de outras cidades para fazer vida no povoado. Tudo indica que o José Veneno representava a figura do intermediário no comércio erótico entre o cliente e a prostituta, estruturando assim uma relação onde a mulher era vista como uma mercadoria de consumo e produção no mundo da noite. Percebe-se que as atividades das mulheres 'rapa-bolso' eram administradas por um terceiro, nesse caso o José Veneno, que em troca de local e serviços derivados, retirava parte de seus ganhos e lucros pela exploração dessas mulheres.

Como podemos notar de acordo com os depoimentos orais, o José Veneno nunca agia sozinho, pois frequentemente era auxiliado em grande parte por figuras dos poderes locais como fazendeiros, políticos, policiais e comerciantes. Esses grupos poderosos a todo o momento buscavam gastar suas riquezas com diversão, lazer, jogos de azar, bebida, entretenimento fácil e principalmente com prazeres libidinosos. José Veneno desempenhava o papel de negociador das relações comerciais entre as mulheres 'rapa bolso' e os seus clientes, pois dessa maneira a prostituição vai se firmando como um mercado de comércio erótico no povoado Rapa Bolso.

Ao que se observa grande número de mulheres trazidas para realizar a prostituição no povoado Rapa Bolso eram oriundas de cidades vizinhas - Amargosa, Castro Alves e Santo Antônio de Jesus, como da Bahia (como era chamada Salvador). De acordo com as narrativas orais, as prostitutas algumas já eram do povoado e outras chegavam sexta-feira a tarde, quando iniciavam o movimento, com a chegada dos tropeiros e voltavam na segunda-feira pela manhã da semana seguinte, com algumas delas permanecendo mais dias no povoado.

Dentre os motivos que levavam as prostitutas a serem agenciadas e a migrarem para o povoado Rapa Bolso, conseguimos elencar alguns. De um lado estava a situação de pobreza encarada por essas mulheres como a dificuldade de ingressar no mercado de trabalho, o que faziam do mundo da prostituição uma alternativa de sua própria sobrevivência. Essa realidade fica mais evidente a partir dos depoimentos, que põem em xeque a difícil batalha cotidiana das mulheres 'rapa bolso' e a ação do agenciador José Veneno que se utilizava de vários artifícios com o fim de arregimentar prostitutas, para o exercício da prostituição.

José Veneno era homem branco, alto, sarará, tinha família, comerciante, lavrador, era vendedor, viajava muito e conhecia vários lugares, por essa razão trazia muitas mulheres da vida para o Rapa Bolso. Fazia as casas de palha para alugar as mulheres da vida. As casas eram de vara de assa-peixe, madeira, sapé, as camas eram de tabua, tirava palha de palmeira na serra chamada de andaiá. A casa tinha um quarto, uma sala, uma cozinha e o chão era todo de barro pisado e era uma mistura de venda e bar. Em função do protagonismo de José, uma das ruas do povoado Rapa Bolso passa a ser chama de Rua do Veneno, que mais tarde ganha uma outra representação simbólica dada pelas mulheres casadas que afirmam que as mulheres 'rapa-bolso' eram venenosas.

Um outro fator que faz as mulheres prostitutas a migrarem para o Rapa Bolso, com objetivo de fazer o comércio erótico nesse povoado, nos faz, portanto, levantar a hipótese de que foram pressionadas a sair da capital em grande parte pelas campanhas repressivas com medidas de higienização física e moral dos espaços públicos levadas a efeito na Bahia durante o governo de J.J. Seabra (1912 - 1916 e 1920 -- 1924), o que fez com que as prostitutas procurassem outras cidades e povoados do interior para fazerem $o$ comércio de seu corpo.

\section{Vamos Botar o Sirigó no Trapiá: Representações Sociais no Território da Prostituição do Rapa-Bolso}

O título dado a este capítulo é uma metáfora referente ao momento em que a mulher e o homem se colocam dispostos a realizarem o ato sexual, mesmo sendo numa relação comercial. A referência feita ao sirigó é uma analogia a uma espécie de cipó utilizado na fabricação de diversos produtos artesanais, sendo comparado com o pênis do homem. Já o trapiá faz referência a uma cuia feita de madeira para apanhar

Renilton da Silva Sandes 
água, sendo comparada com a vagina da mulher. No entanto, na memória dos sujeitos pesquisados, não raras vezes aparecia à expressão 'vamos botar o sirigó no trapiá', que simbolizava, metaforicamente, a procura pelos clientes dos serviços sexuais das mulheres 'rapa bolso', fazendo-nos pensar em algumas das práticas e representações sociais, suscitando provocações no sentido de perceber qual era a motivação da procura desses espaços e territórios dos desejos e do prazer. Neste item busca-se analisar, a partir das representações sociais, cinco espaços no quais foram demarcados os territórios da prostituição no povoado Rapa Bolso, classificados aqui como consagrados territórios dos desejos e do prazer, em seus diversos conteúdos e significados.
A força das mulheres do Rapa-bolso possibilitou a organização de verdadeiros territórios nos distintos espaços que faziam à composição das ruas do povoado Rapa Bolso. Nestes espaços as mulheres 'rapa-bolso' delimitavam seus territórios, principalmente, a partir do uso e ocupação das distintas ruas, como também estavam localizadas nas esquinas, nas praças, feiralivre, em quitandas, espaços compreendidos entre as principais ruas em que se exerciam a prostituição. Foi possível identificar através do recolhimento de vários depoimentos o significado simbólico e material dado ao nome das ruas e o número aproximado de casas de prostituição, estando distribuídas espacial e territorialmente da seguinte forma:

- A Rua da Arrepiada - hoje Rua XV de Novembro - era chamada assim, visto que tinha muita bagunça e briga entre os tropeiros por causa das mulheres 'rapa bolso' e também porque essas mulheres deixavam seus cliente todos arrepiados ou 'arrupiados', tendo cerca de 13 a 15 casas de palha. ',

Figura 02:
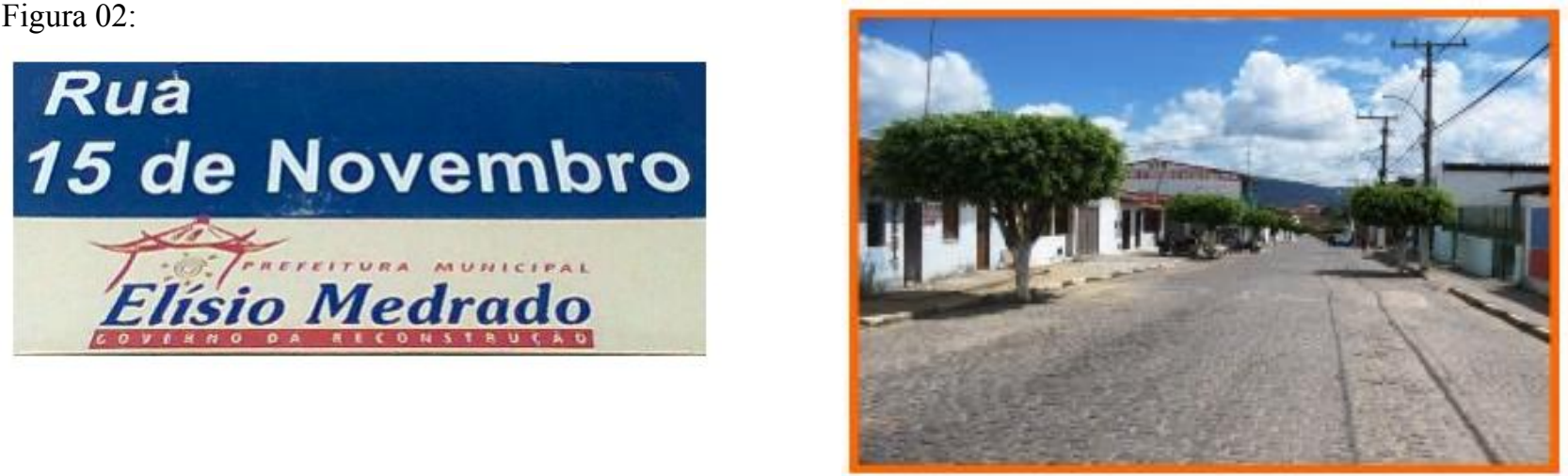

- A Rua do Veneno - hoje Rua Nossa Senhora de Fátima - era chamada assim, porque as mulheres 'rapa-bolso' eram vistas como 'venenosas' que disseminavam o veneno, no modelo de família nuclear patriarcal e também por causa do cafetão chamado de José Veneno, tendo cerca de 11 a 13 casas de palha.

Figura 03:

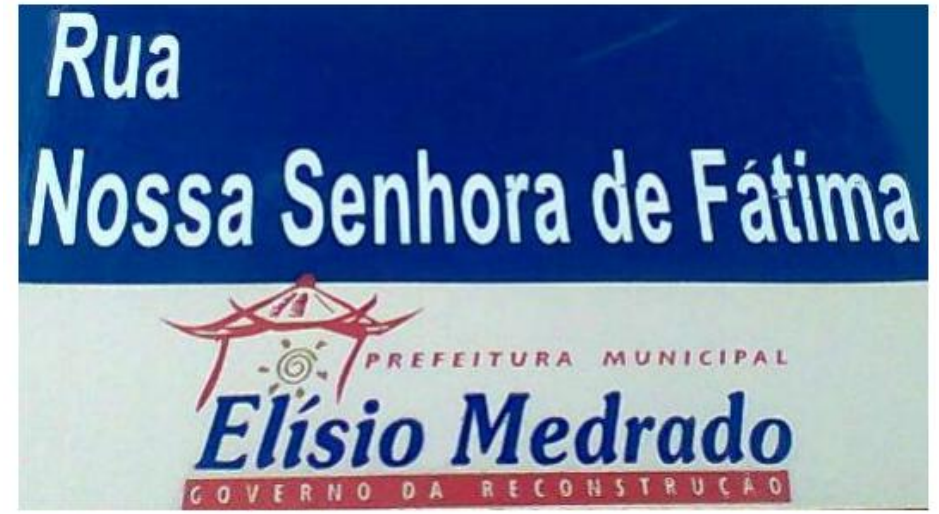

Renilton da Silva Sandes 
Representações Sociais no Território de Elísio

Medrado Marcada pelas Práticas de Prostituição

das Mulheres 'Rapa-Bolso'

- A Rua do Tranca Cu - hoje Rua Genésio Braga - era chamada assim, em função da prática do sexo anal, tendo cerca de 10 a 12 casas de palha e sapé.

Figura 04:

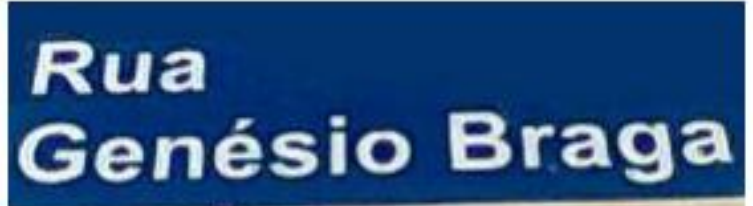

Elisio Medrado

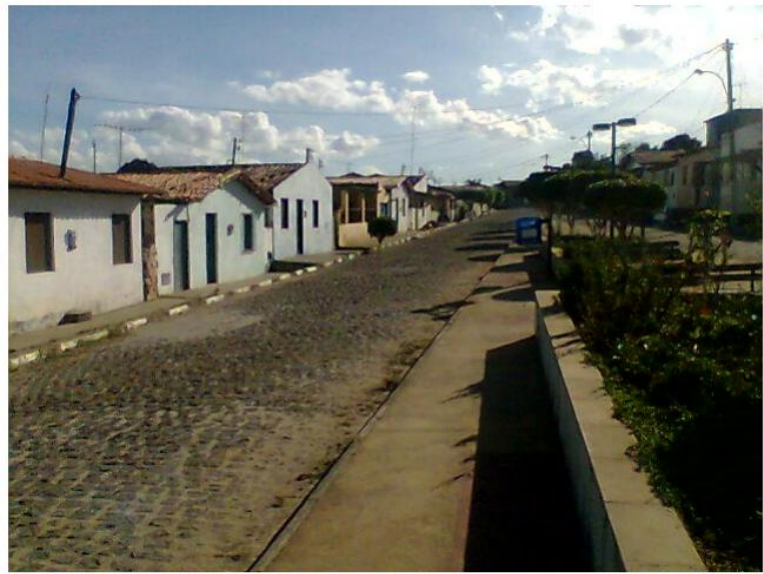

- A Rua do Pinga Pus - hoje Rua Moises Santos - era chamada assim, porque tinha muitas doenças venéreas, tendo 9 a 11 casas de palha.

Figura 05:

\section{Rua \\ Moises Santos}
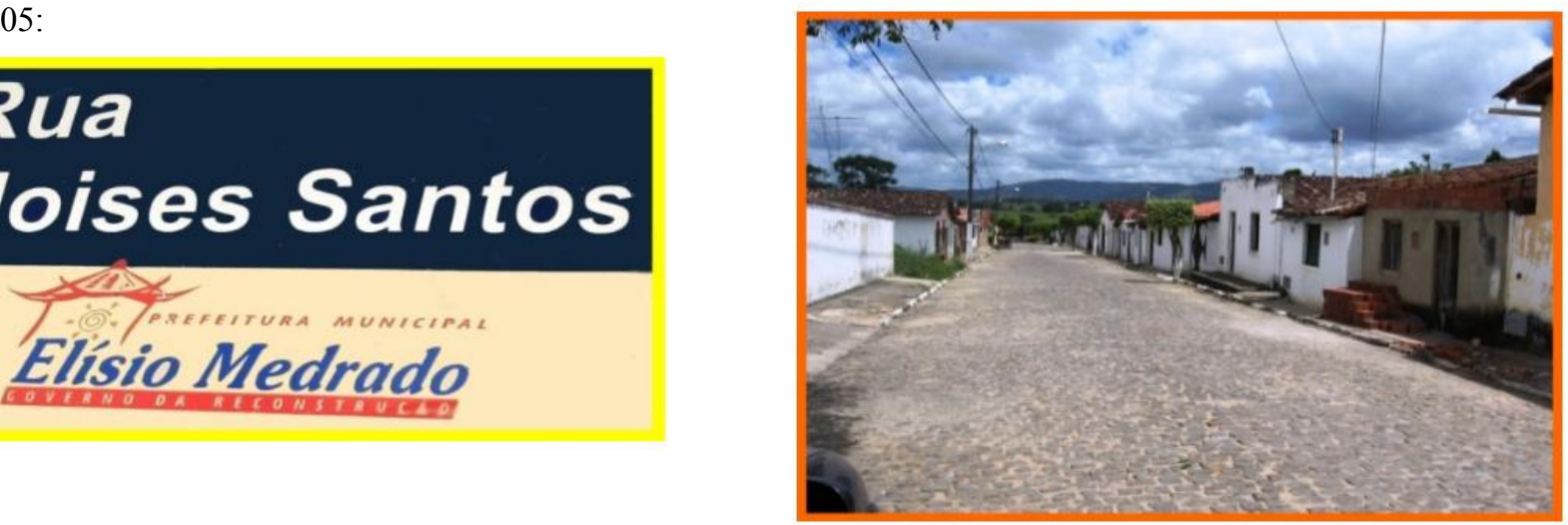

- A Rua da Palha - hoje Rua Santo Antônio - era chamada assim, porque as casa eram de palhas e sapé - tinha cerca de 8 a 10 casas de palhas.

Figura 06:
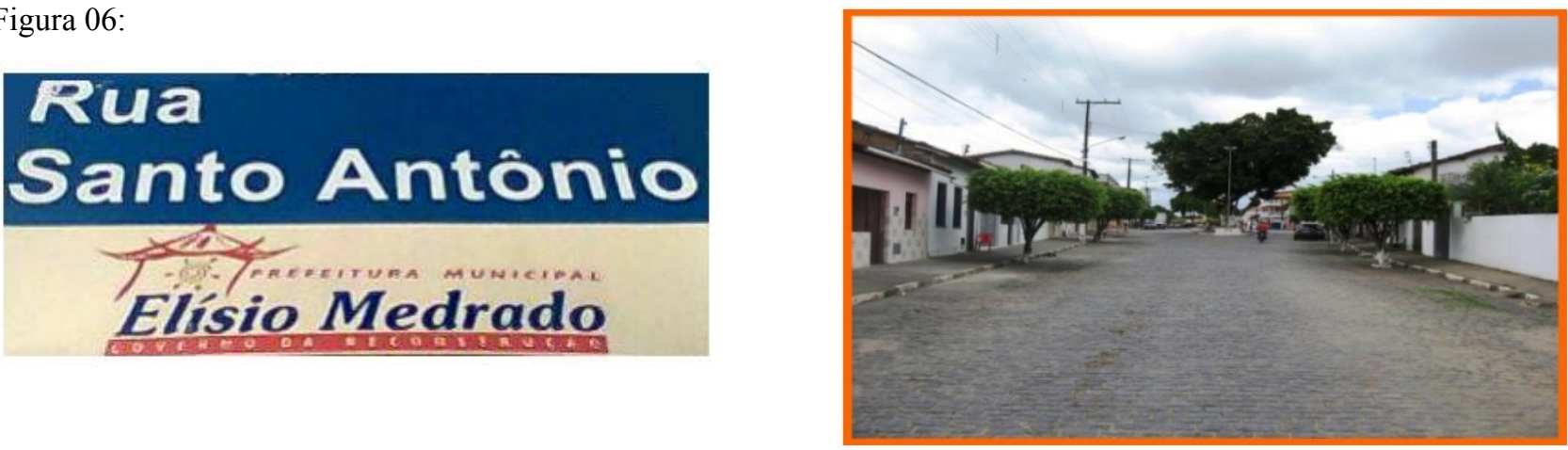

Renilton da Silva Sandes 
As ruas do Rapa Bolso foram a matéria-prima que as atrizes sociais utilizaram para produzir o território. Assim, a transformação do espaço em território acontece por meio da conflitualidade, definida pelo estado permanente de negociações geradas no enfrentamento entre as mulheres 'rapa bolso' e o poder hegemônico local que procuram controlar certas porções do território. É no bojo desse contexto que emergem as análises sobre as ações cotidianas das prostitutas na ocupação e uso do território, não apenas como um triunfo que marca e delimita uma área, mas também como meio essencial de elaboração de suas estratégias de sobrevivências frente à exclusão social que foram postas pela sociedade machista patriarcal.

O meretrício organizado pelas mulheres 'rapa bolso' tem sido representado ora como os espaços e territórios da contraordem, da algazarra, da bagunça, ora como espaços dos prazeres libidinosos, da diversão, do lazer, como dos jogos de azar, da bebida, da música, do entretenimento fácil e porque não, admitir que significasse um espaço alternativo à sexualidade conjugal. O depoimento abaixo, confirma como as representações sociais são apropriadas pelos sujeitos sociais pesquisados, nas distintas relações cotidianas individuais e coletivas:

Em pleno calor do verão, numa sexta-feira do mês de janeiro de 1945, por cerca das 17h30min, a Rua da Arrepiada foi cenário de uma grande agitação. A meretriz Zurmira, de cor negra, com 20 anos de idade, originaria de Amargosa estava atentando contra o pudor na referida rua, quando, após uns goles de cachaça, alterando a consciência e o comportamento, ficou completamente nua, para mostrar seu corpo no intuito de atrair e seduzir os clientes, tropeiros viajantes que terminara de chegar ao povoado Rapa Bolso. Tal cena causando grande escândalo fez com que o delegado Belmiro Francisco de Souza e o Inspetor João José interviessem $e$ prendessem a mulher 'rapa-bolso'. ${ }^{3}$

Cenas como esta, diz o sujeito pesquisado, eram constantes no povoado Rapa Bolso, pois a prostituição era uma prática de comércio erótico com presença marcante nos distintos espaços e territórios alternativos dos desejos e do prazer. Nas quitandas, nos becos, na praça, na feira-livre, nas ruas e nos prostíbulos organizados em casas de palhas, lá estavam às mulheres 'rapa-bolso'.

Segundo depoimento, em novembro de 1941,
Otacílio Souza, com 23 anos, branco, noivo recebeu dois ferimentos de navalha. A autora do feito, a 'rapabolso' Santinha, com aproximadamente, 29 anos, de cor negra e residente na Rua da Arrepiada. Ele era frequentador das casas das mulheres 'rapa bolso' e, por conta disto, após uma bebedeira, não cumpriu com o pagamento do serviço sexual prestado, fato que gerou grande ira na 'rapa bolso' Santinha e, num rápido 'descontrole emocional', mas dentro de sua razão, vibro-lhe duas navalhadas, uma no pescoço e a outra no rosto de seu cliente. Os depoimentos deixam claro como as mulheres 'rapa-bolso', estavam investidas por um forte poder de negociação que às permitiam burlar e driblar as medidas de controle e vigilância pregadas pelo poder hegemônico local patrimonialista, frequentemente com a cumplicidade das autoridades policiais que ora exercia um papel repressor ora de extorsão, no caso das prostitutas. Assim, as ruas para as mulheres 'rapa-bolsos' significavam espaços e territórios cotidianos que legitimaram a conquista da liberdade e a manutenção de sua sobrevivência através do dinheiro arduamente ganho no comércio erótico.

\section{Últimas Reflexões para Novas Discussões sobre Geografia do Gênero}

O Rapa Bolso não acaba. O conhecimento do Rapa Bolso é grande, a gente se acaba e a história fica para os outros contar.

Em que pese a especificidade do cotidiano da prostituição nas ruas do povoado Rapa Bolso, o presente capítulo é um esforço de analisar as ações e as pequenas negociações diárias das mulheres 'rapa bolso' frente às dificuldades de toda ordem de sobrevivência, como também uma alternativa de andar na contramão dos valores tradicionais, preferindo a vida livre à vida obscura da casa e do lar. No entanto, não pretendemos esgotar todas as questões teóricas e metodológicas que envolvem o estudo dessa atividade tão antiga quanto à própria civilização. Para muitos, as prostitutas são a fuga de casamentos falidos, de casamentos sem diálogo. Para outros são o câncer da sociedade, que concebe a prostituição como atividade transgressora em relação à conduta sexual dita moral, elaborada e produzida pelo imaginário social. Enfim, um tema sempre polêmico, e, de certo modo, muito antigo.

Enfim, o presente trabalho oferece uma análise das representações sociais permeada pela geografia do gênero e forma parte da primeira fase da pesquisa sobre como essa territorialidade é construída pelas mulheres 'rapa bolso' - mulheres, majoritariamente negras - que exerciam a prostituição na comunidade de

Renilton da Silva Sandes 
Elísio Medrado na época pós-abolição e pós-colonial. A análise aponta para as relações de poder e suas interferências com as relações de gênero na configuração do espaço urbano de Elísio Medrado até o ponto de haver tido a denominação de Rapa-Bolso. Frente ao poder hegemônico há sempre um movimento contra-hegemônico e, nesse sentido, podemos considerar as mulheres rapa-bolso como atores sociais que desafiaram os poderes instituídos - o poder municipal e a igreja católica, os quais demarcaram um território em Elísio Medrado, fato ainda vivo no imaginário coletivo da comunidade.

A pesquisa aponta também para a necessidade de atender tanto as relações de poder como às de gênero recordemos que o gênero implica em relações de poder do homem sobre a mulher, a imposição do masculino sobre o feminino - na construção da territorialidade no espaço urbano, pois estas relações potencializam assim como dificultam, ou seja, interferem diretamente, no desenvolvimento local que tanto hoje em dia preocupa à academia, ao poder público e a sociedade como um todo. É reconhecido, e os movimentos de mulheres como os clubes de mães e as creches comunitárias estão como testemunha, o protagonismo que as mulheres das classes populares no sustento das famílias e, consequentemente, na construção dos espaços cotidianos e públicos como extensão do lar 'o pessoal é político' nos lembra o lema do feminismo. Este fato continua desafiando o poder estabelecido porque nossa cultura continua sendo predominantemente patriarcal e na Bahia ainda patrimonialista.

1 Derita Maia, 78 anos. Entrevista concedida em 20 de Junho de 2007 a Renilton da Silva Sandes. Acervo do autor.

2 Maria Aurelina Santos Silva, 70 anos. Entrevista concedida em 25 de Outubro de 2007 a Renilton da Silva Sandes. Acervo do autor.

3 Antônio Nunes Souza, 79 anos. Entrevista concedida em 09 de Julho de 2007 a Renilton da Silva Sandes. Faz parte do acervo do autor.

\section{Referências}

BEAUVOIR, Simone de. O Segundo Sexo: A Experiência Vivida. Buenos Aires: Ediciones Siglo XX, 1987.

CAMPOS, Andrelino. Do quilombo à favela: a produção do espaço criminalizado em Rio de Janeiro. Rio de Janeiro:Bertrand Brasil, 2005.

CHARTIER, Roger. A História Cultural: entre práticas e representações. Rio de Janeiro: Editora Bertrand S/A, 1990.

CLAVAL, Paul. A Geografia Cultural: O estado da arte. In: ROSENDAHL, Zeny; CORRÊA, Roberto L. (Orgs.). Manifestações da cultura no espaço. Rio de Janeiro: EdUERJ, 1999, p.59-57.

GOFFMAN, Erving. A Representação do Eu na Vida Cotidiana. Petrópolis: Vozes, 1985.

HAESBAERT, Rogério. Territórios Alternativos. EDUFF, S.P: Contexto, 2002.

MARTÍNEZ, Ana S.; MOYA, Juana Ma . R.; MUÑOZ, $M^{\mathrm{a}}$. Ángeles D. Mujeres, Espacio y Sociedad: Hacia una Geografía del Género. Madrid: Editorial Síntesis, 1995.

PRIORE, Mary Del. A Mulher na História do Brasil. São Paulo: Atlas, 1988.

RAfFESTIN, Claude. Por uma Geografia do Poder. São Paulo: Ática, 1993.

SAFFIOTI, Heleith Iara Bongiovani. A Mulher na Sociedade de Classes: Mito e Realidade. Petrópolis: Vozes, 1976.

SANTOS, Milton. O território e o saber local: algumas categorias de análise. In: Cadernos IPPUR, ano XIII, n. 2, p. 15 - 26, ago-dez, 1999.

A natureza do Espaço: Tempo e técnica. Razão e emoção. São Paulo: Hucitec, 1996.
Recebido em 08 de maio de 2010. Aceito em 07 de novembro de 2011.

Renilton da Silva Sandes 